\title{
The Medial Temporal Lobe Memory System
}

\author{
Larry R. SQUire and Stuart Zola-Morgan
}

\begin{abstract}
Studies of human amnesia and studies of an animal model of human amnesia in the monkey have identified the anatomical components of the brain system for memory in the medial temporal lobe and have illuminated its function. This neural system consists of the hippocampus and adjacent, anatomically related cortex, including entorhinal, perirhinal, and parahippocampal cortices. These structures, presumably by virtue of their widespread and reciprocal connections with neocortex, are essential for establishing long-term memory for facts and events (declarative memory). The medial temporal lobe memory system is needed to bind together the distributed storage sites in neocortex that represent a whole memory. However, the role of this system is only temporary. As time passes after learning, memory stored in neocortex gradually becomes independent of medial temporal lobe structures.
\end{abstract}

$\mathrm{I}$ N 1957, SCOVILle ANd Milner Described A PROFOUND and selective impairment in human memory after bilateral surgical removal of the medial temporal lobe (1). Comprehensive neuropsychological evaluation of one patient from that series (patient H.M.) established the fundamental principle that the ability to acquire new memories is a distinct cerebral function, separable from other perceptual and cognitive abilities (2). Memory impairment has also been linked to medial temporal lobe damage in cases of viral encephalitis (3), posterior cerebral artery occlusion (4), and Alzheimer's disease (5). However, the medial temporal lobe is a large region that includes the hippocampal formation (6), the amygdaloid complex, and adjacent cortical areas (Fig. 1). It has therefore been difficult to determine from human cases precisely which structures and connections within the medial temporal lobe are important for memory.

\section{Human Memory: Anatomical Findings Since Patient H.M.}

Initially, attention was drawn to the hippocampal region (6) because patients who underwent temporal lobe surgery developed memory impairment only when the removal extended far enough posteriorly to include the hippocampus and the parahippocampal gyrus $(1,7)$. Several single-case reports also linked memory impairment to hippocampal lesions (8). However, in these cases memory functions were usually assessed informally, and the damage in most cases was not confined to the hippocampus.

The picture was also complicated for a time by findings from

The authors are at the Veterans Affairs Medical Center, San Diego, CA 92161 and in the Department of Psychiatry, University of California, San Diego, La Jolla, CA 92039. behavioral studies of rats, monkeys, and other animals with hippocampal lesions, which were initiated after patient H.M. was first described but which could not be easily interpreted in terms of impaired memory (9). In 1978, two alternatives were proposed to the view that the hippocampus itself is critical for memory functions. Horel proposed that memory functions were disrupted, not by hippocampal damage, but by damage to temporal stem white matter, which lies near the hippocampus just above the lateral ventricle. He suggested that the temporal stem would necessarily have been damaged by the surgical procedure used to remove the medial temporal lobe in humans and monkeys (10). An alternative view was presented by Mishkin on the basis of findings from monkeys with extensive medial temporal lobe ablations, similar to

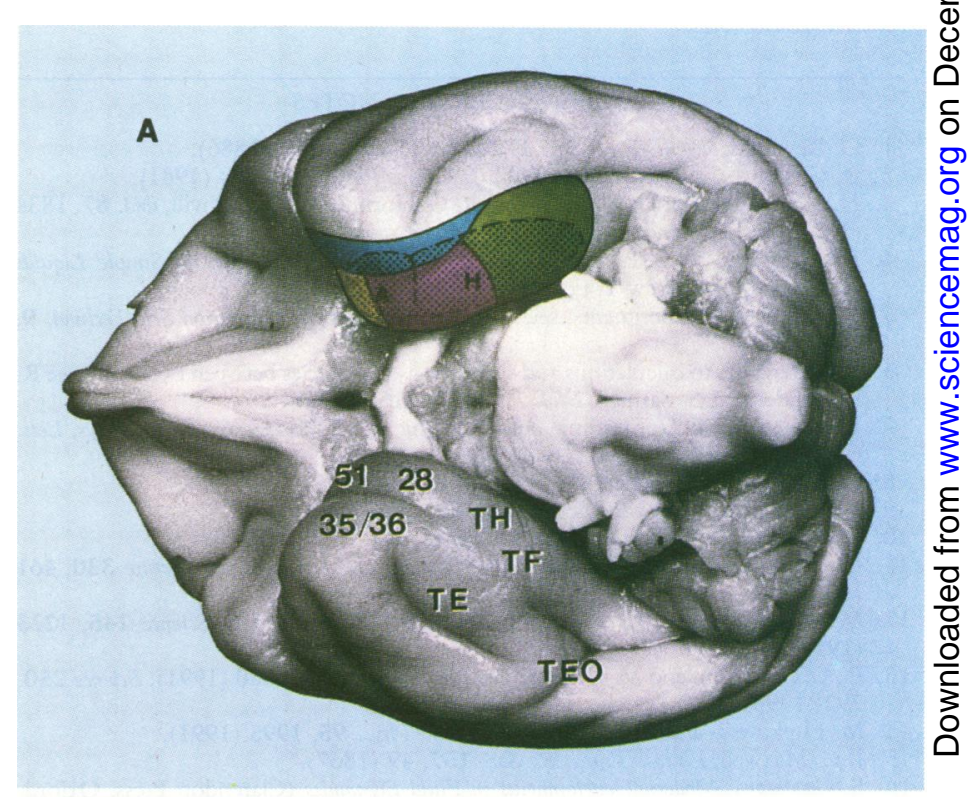

Fig. 1. (A) Ventral view of a monkey brain showing the components of the large $\mathrm{H}^{+} \mathrm{A}^{+}$lesion that first established an animal model of human amnesia. This view shows the amygdala (A) and hippocampus $(\mathrm{H})$, both in crosshatching, and adjacent cortical regions $(+)$ included in the $\mathrm{H}^{+} \mathrm{A}^{+}$surgery. Blue, perirhinal cortex (areas 35 and 36 ); yellow, periamygdaloid cortex (area 51); pink, entorhinal cortex (area 28); green, parahippocampal cortex (areas TH and TF). (B) A schemat-

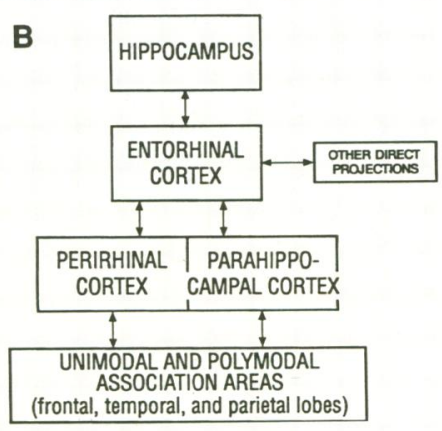
ic view of the medial temporal lobe

memory system. The entorhinal cortex is the major source of projections to the hippocampus. Two-thirds of the cortical input to the entorhinal cortex originates in the adjacent perirhinal and parahippocampal cortices, which in turn receive projections from unimodal and polymodal areas in the frontal, temporal, and parietal lobes. The entorhinal cortex also receives other direct inputs from orbital frontal cortex, cingulate cortex, insular cortex, and superior temporal gyrus. All these projections are reciprocal. 
the surgical lesion sustained by patient H.M. He proposed that conjoint damage to both the hippocampus and amygdala is required to produce severe amnesia in monkeys and humans (11). This proposal was consistent with the fact that all the human surgical cases with amnesia had damage to both the hippocampus and amygdala $(1,7)$.

In 1986, a role for the hippocampus itself in human memory was established from a case of amnesia (12). Patient R.B. developed memory impairment in 1978 at the age of 52, after an episode of global ischemia. He survived for 5 years, during which time he had significant memory impairment in the absence of other cognitive dysfunction. Upon his death, histological examination of the brain revealed a circumscribed bilateral lesion involving the entire rostrocaudal extent of the $\mathrm{CAl}$ field of the hippocampus. Studies of animal models of global ischemia in the rodent have confirmed the vulnerability of CAl neurons in the hippocampus to ischemia and implicated a mechanism for this selective lesion that involves the excitotoxic effects of a glutamate neurotransmitter (13). Findings from patient R.B. allowed two conclusions. First, the hippocampus itself appeared to be a critical component of the medial temporal lobe memory system. This idea was later supported by an additional case in which memory impairment was associated with a bilateral lesion confined to the hippocampus (14). Second, because R.B. was not as severely amnesic as H.M. (15), other hippocampal regions in addition to the CAl field, or structures outside the hippocampus, must be important for memory functions.

Further confirmation for these ideas has come from improvements in magnetic resonance imaging (MRI), which make it possible to obtain anatomical information from living patients (Fig. 2, A and B). With the use of high-resolution MRI, the hippocampal region (defined in those studies as the fimbria, dentate gyrus, hippocampus proper, and subiculum) was found to be shrunken and atrophic (57\% of normal size) in four amnesic patients $(16,17)$. The temporal lobe was of normal size. Because these patients were not as memory-impaired as patient H.M., the findings with MRI reinforce
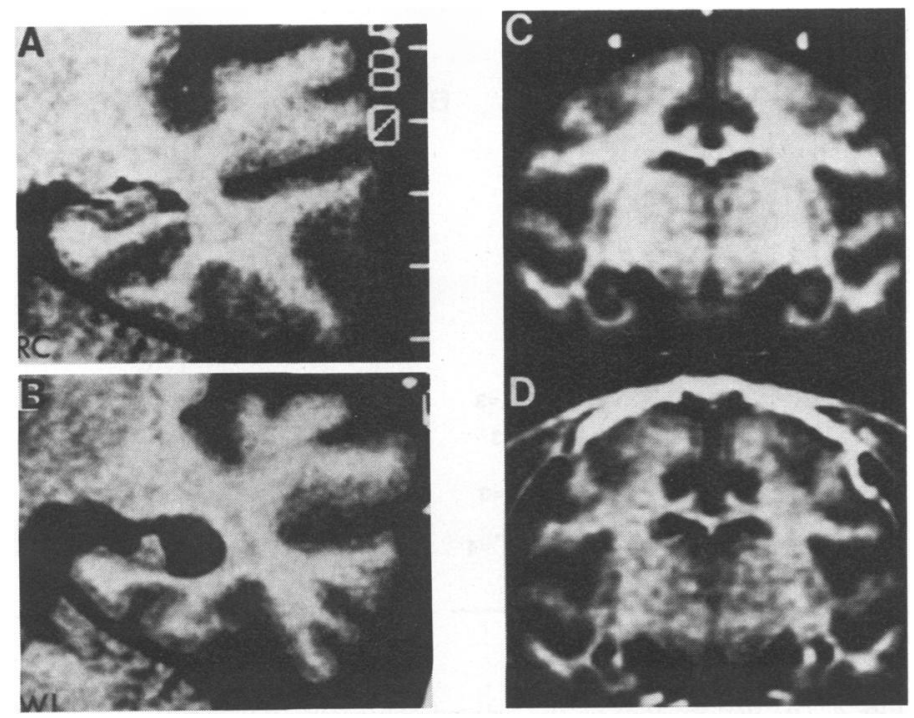

Fig. 2. (A) A Tl-weighted MR coronal image from a healthy normal subject (R.C.) at the level of the left hippocampal formation. (B) An image at the same level as in (A) in a severely amnesic patient of the same age (W.I.). Note the markedly shrunken hippocampal formation in the patient. (C) A coronal image of a monkey brain showing three $\mathrm{CuSO}_{4}$-filled beads (white circles) anchored to the skull, which were used as landmarks to establish stereotaxic coordinates for making hippocampal lesions. (D) An image of the same monkey as in (C) after the hippocampal lesion. The image is in a plane perpendicular to the long axis of the hippocampus. [Reprinted from (17) and (47) with permission, (O) 1990 Oxford University Press]

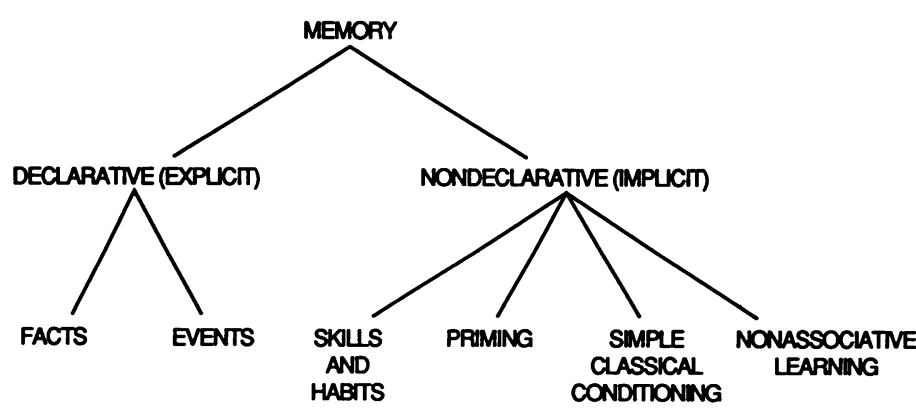

Fig. 3. Classification of memory. Declarative (explicit) memory refers to conscious recollections of facts and events and depends on the integrity of the medial temporal lobe (see text). Nondeclarative (implicit) memory refers to a collection of abilities and is independent of the medial temporal lobe (60). Nonassociative learning includes habituation and sensitization. In the case of nondeclarative memory, experience alters behavior nonconsciously without providing access to any memory content $(19,20)$.

the conclusion that structures in addition to the hippocampus itself are likely to be important for memory functions.

\section{Development of the Animal Model}

In the early 1980s, an animal model of human amnesia became available in the nonhuman primate $(11,18)$. The animal model made it possible to investigate systematically which anatomical structures are important for memory. The research strategy is straightforward. $ᄃ$ Monkeys can be prepared with bilateral, circumscribed lesions limited to a particular structure or combination of structures. The $\overline{0}$ effects of the removals on memory are then determined quantita- 8 tively by evaluating the performance of these monkeys on tasks that $\varepsilon$ are identical to, or in some cases analogous to, tasks used to detect $\circlearrowright$ memory impairment in human patients. To determine whether the $\frac{\mathcal{O}}{\mathcal{O}}$ impairment in monkeys is long-lasting, as it is in humans after $\mathrm{c}$. medial temporal lobe damage, monkeys can be tested several years after surgery.

One of the reasons that it took so long to develop an animal model of human amnesia was that, until the early 1980s, human amnesia itself was incompletely understood, and it was therefore 0 unclear what parallels should be looked for in experimental animals. के It is now appreciated that memory is not a single faculty but is 0 composed instead of multiple separate systems, only one of which is impaired in amnesia (19). Accordingly, only certain kinds of memory tests are appropriate for demonstrating an impairment in animals that corresponds to human amnesia.

Human amnesia impairs the ability to acquire information about facts and events (declarative memory) but spares the capacity for skill learning, certain kinds of conditioning and habit learning, as well as the phenomenon of priming (Fig. 3). Declarative memory is accessible to conscious recollection and available to multiple response systems. Nondeclarative (implicit) memory includes several kinds of abilities, all of which are nonconscious and expressed through performance. These abilities provide for cumulative changes in perceptual or response systems and for the development of new skills and habits. The information is not accessible to conscious recollection, and it is inflexible, that is, it has limited access to systems not involved in the initial learning. The idea that the medial temporal lobe is involved in only one kind of memory also developed in the animal literature $(20,21)$, and the findings from humans and experimental animals are now in substantial agreement that limbic lesions have selective and specific effects on memory (22).

The development of the animal model in the monkey began with large bilateral lesions of the medial temporal lobe that approximated 
Table 1. Characteristics of human amnesia that have been produced in monkeys with large bilateral lesions of the medial temporal lobe (the $\mathrm{H}^{+} \mathrm{A}^{+}$lesion).

\section{Characteristics}

1. Memory is impaired on several tasks including ones identical to those failed by amnesic patients.

2. Memory impairment is exacerbated by increasing the retention delay or the amount of material to be learned.

3. Memory impairment is exacerbated by distraction.

4. Memory impairment is not limited to one sensory modality.

5. Memory impairment can be enduring.

6. Memory for events prior to the onset of amnesia can be affected (retrograde amnesia).

7. Skill-based memory is spared.

8. Immediate memory is spared.

the damage sustained by amnesic patient H.M. (11, 23-25). The lesion was produced by means of a direct surgical approach through the ventral surface of the temporal lobe, and the damaged area included the hippocampal formation (that is, the dentate gyrus, the hippocampus proper, the subicular complex, and the entorhinal cortex), the amygdala, and the surrounding perirhinal and parahippocampal cortices (Fig. 1A). This has been termed the $\mathrm{H}^{+} \mathrm{A}^{+}$lesion (26), where $\mathrm{H}$ refers to the hippocampus, $\mathrm{A}$ to the amygdala, and ${ }^{+}$ to the cortical regions adjacent to the hippocampus and the amygdala.

The $\mathrm{H}^{+} \mathrm{A}^{+}$lesion in monkeys reproduced many important features of the memory impairment in patient H.M. and in other amnesic patients (Table l). Like human amnesic patients, monkeys were severely impaired on a number of memory tasks but were entirely normal at acquiring and retaining skills. Although many tasks have been used to demonstrate impaired memory in monkeys (27), the one most widely used has been the delayed nonmatching to sample task. In this test of recognition memory, a single object is presented and then after a delay two objects are presented, the original object and a novel one. The animal must choose the novel object to obtain a food reward. Unique pairs of objects are used on every trial.

In an early comparison of $\mathrm{H}^{+} \mathrm{A}^{+}$lesions with lesions of the white matter that forms the temporal stem, only the $\mathrm{H}^{+} \mathrm{A}^{+}$lesions impaired memory (23). This result suggested that the structures of the medial temporal lobe were critical for recognition memory, not the white matter that connects lateral temporal neocortex to diencephalic and other subcortical targets (28).

\section{Contributions of Hippocampus, Amygdala, and Adjacent Cortex}

A lesion of the posterior medial temporal lobe (the $\mathrm{H}^{+}$lesion) also impairs memory (Fig. 4), albeit less severely than the $\mathrm{H}^{+} \mathrm{A}^{+}$ lesion $(11,25,29-31)$. The $\mathrm{H}^{+}$lesion was limited to the hippocampal formation and the parahippocampal cortex, and it spared the anterior portion of the entorhinal cortex together with the amygdala and other cortex adjacent to the amygdala. Monkeys with $\mathrm{H}^{+}$ lesions that were first trained before surgery and then tested after surgery $(11,32)$ performed better than monkeys that were both trained and tested after surgery $(29-31,33)$. Nevertheless, the $\mathrm{H}^{+}$ lesion produced statistically significant memory impairment in mon- keys, even after preoperative training. Moreover, in human patients $(12,14)$ even more restricted lesions can produce clinically meaningful memory impairment.

There are three possible explanations for why memory in monkeys was more impaired after $\mathrm{H}^{+} \mathrm{A}^{+}$lesions than after $\mathrm{H}^{+}$ lesions. As the $\mathrm{H}^{+}$lesion was extended anteriorly to include the $\mathrm{A}^{+}$component, the memory impairment could have been exacerbated either by the amygdala damage (A), the damage to cortex adjacent to the amygdala $\left({ }^{+}\right)$, or the combination of amygdala and cortical damage $\left(\mathrm{A}^{+}\right)$. The experimental evidence favors the second of these alternatives, that is, the additional impairment results from damage to cortex adjacent to the amygdala (Fig. 4). An important clue came from a group of monkeys with stereotaxic lesions of the amygdaloid complex that spared the surrounding cortex (the A lesion). Monkeys with the A lesion performed normally on the delayed nonmatching to sample task and on three other memory tasks, all of which are sensitive to the effects of $\mathrm{H}^{+}$ or $\mathrm{H}^{+} \mathrm{A}^{+}$lesions (34). Moreover, monkeys with bilateral lesions of the hippocampal formation, made conjointly with circumscribed lesions of the amygdaloid complex (the $\mathrm{H}^{+}$A lesion), werso impaired on these same four memory tasks, but the impairmen was no greater after $\mathrm{H}^{+} \mathrm{A}$ lesions than after $\mathrm{H}^{+}$lesions (34). Thus, amygdala damage alone did not impair memory nor did exacerbate the memory impairment associated with hippocampag formation lesions.

Experiments with rodents have led to the same conclusione Hippocampal lesions, or lesions of anatomically related structures impair performance on a variety of spatial and nonspatial memor tasks. However, amygdala lesions do not impair performance oß these same tasks, nor does the addition of an amygdala lesion to lesion of the hippocampal system exacerbate the deficit (35). The findings for rats and monkeys, taken together, suggest that the severe memory impairment associated with $\mathrm{H}^{+} \mathrm{A}^{+}$lesions should be attributed, not to the addition of the amygdala to the $\mathrm{H}^{+}$lesion, bue instead to the addition of cortical regions that lie adjacent to the amygdala and that are necessarily damaged when the amygdala is removed by the conventional surgical approach.
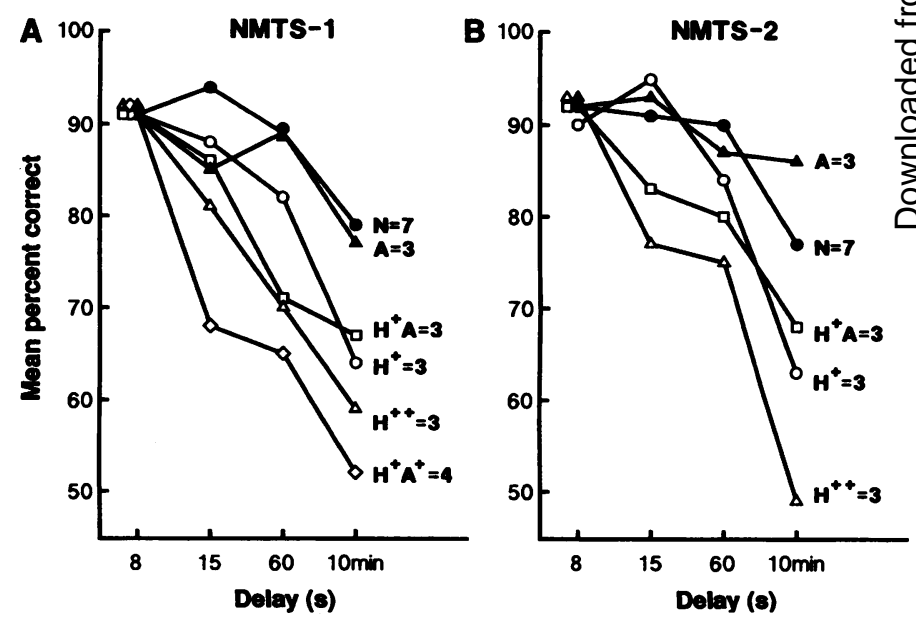

Fig. 4. (A) Performance on the delayed nonmatching to sample task 6 to 8 weeks after surgery by seven normal monkeys $(\mathbf{N})$ and five groups of monkeys with lesions: A, circumscribed lesion of the amygdala sparing surrounding cortex; $\mathrm{H}^{+}$, lesion of the hippocampal formation and parahippocampal cortex; $\mathrm{H}^{+} \mathrm{A}$, a combination of these two lesions; $\mathrm{H}^{+} \mathrm{A}^{+}$, lesion of the hippocampus, the amygdala, and adjacent cortical regions, that is, perirhinal, entorhinal, and parahippocampal cortex; $\mathrm{H}^{++}$, lesion of the hippocampus and the same cortical regions damaged in the $\mathrm{H}^{+} \mathrm{A}^{+}$lesion. (B) Performance of the same normal monkeys as in (A) and four of the five groups with lesions on the delayed nonmatching task 1 to 2 years later. At the 10 -min delay in (A) and (B), the SEM ranged from $2.3 \%$ to $4.7 \%$. 
The identity of the critical cortical structures was suggested by a reexamination of the histological material from an early study (23) in monkeys with $\mathrm{H}^{+} \mathrm{A}^{+}$lesions, which showed that the perirhinal and entorhinal cortex adjacent to the amygdala had sustained substantial damage. Neuroanatomical evidence suggests why these cortical regions could be important for memory (Fig. 1B). The perirhinal cortex and the parahippocampal gyrus (areas TH and TF) provide nearly two-thirds of the cortical input to the entorhinal cortex (36). The entorhinal cortex in turn is the source of the perforant path, the major efferent projection to the hippocampus and dentate gyrus. Thus, these cortical regions collectively provide the principal route by which information in neocortex reaches the hippocampus.

We therefore reasoned that extending the $\mathrm{H}^{+}$lesion forward to include anterior entorhinal cortex and the perirhinal cortex, but sparing amygdala (the $\mathrm{H}^{++}$lesion), should exacerbate the deficit produced by the $\mathrm{H}^{+}$lesion and impair memory as much as it is impaired by the $\mathrm{H}^{+} \mathrm{A}^{+}$lesion. This idea has been confirmed. Monkeys with bilateral $\mathrm{H}^{++}$lesions were as severely impaired on the delayed nonmatching to sample task as those with $\mathrm{H}^{+} \mathrm{A}^{+}$ lesions, and the severity of the impairment remained stable for more than 1 year after surgery (Fig. 4) (37). In two testing sessions and with three retention delays (15 s, $60 \mathrm{~s}$, and $10 \mathrm{~min})$, monkeys with $\mathrm{H}^{++}$lesions were more severely impaired than either monkeys with $\mathrm{H}^{+}$lesions $(P<0.05)$ or monkeys with $\mathrm{H}^{+} \mathrm{A}$ lesions $(P<0.05)$. We also reasoned that memory should be severely disrupted by a lesion limited to the perirhinal and parahippocampal cortex (the PRPH lesion), sparing the hippocampus, the amygdala, and the entorhinal cortex (38). Monkeys who sustained the PRPH lesion were severely impaired on all three amnesia-sensitive tasks that were administered. Overall, they appeared about as impaired as monkeys with $\mathrm{H}^{+} \mathrm{A}^{+}$lesions.

The findings with $\mathrm{H}^{++}$and PRPH lesions indicate that damage to the perirhinal cortex, and not damage to the amygdala, contributes to the severe memory impairment associated with $\mathrm{H}^{+} \mathrm{A}^{+}$ lesions. This conclusion requires that damage to perirhinal cortex is substantial in monkeys with $\mathrm{H}^{++}$lesions or PRPH lesions but minimal in monkeys with $\mathrm{H}^{+}$or $\mathrm{H}^{+} \mathrm{A}$ lesions. To address this issue, we measured planimetrically the areas of the entorhinal, perirhinal, and parahippocampal cortices, and the area of the inferotemporal cortex (area TE) (37). The perirhinal cortex was the only area where the $\mathrm{H}^{++}$and PRPH monkeys sustained more damage than the $\mathrm{H}^{+}$ and the $\mathrm{H}^{+} \mathrm{A}$ monkeys. In the monkeys with $\mathrm{H}^{+}$or $\mathrm{H}^{+} \mathrm{A}$ lesions, less than $25 \%$ of the perirhinal cortex was damaged bilaterally. In the monkeys with $\mathrm{H}^{++}$lesions, however, approximately $74 \%$ of the perirhinal cortex was damaged bilaterally. In addition, in the monkeys with PRPH lesions, approximately $68 \%$ of the perirhinal cortex was damaged.

These investigations permit the main components of the medial temporal lobe memory system to be identified. The memory system consists of the hippocampal formation, including entorhinal cortex,

Fig. 5. Dissociation of emotion (E) and memory (M) by lesions of the amygdala and the hippocampal formation. The emotion score was obtained by measuring the responsiveness of monkeys to seven inanimate stimuli that could elicit investigatory or consummatory behavior. The memory score is the score on the delayed nonmatching to sample task at a 10-min delay. Normal, performance by 15 normal monkeys; $A$ and $H$, performance by two groups of monkeys with damage to both the hippocampal formation and the amygdala (total $n=10$ ); A, performance by two groups of monkeys with damage to the amygdala but not the hippocampal formation (total $n=7$ ); $\mathrm{H}$, performance by two groups of monkeys with damage to the hippocampal formation or associated cortical areas or both, but not the amygdala (total $n$ $=10$ ). Error bars show the SEM. [Reprinted from (42) with permission, (c) 1991 Churchill Livingstone] together with the adjacent, anatomically related perirhinal and parahippocampal cortices (Fig. 1B). Importantly, the cortex adjacent to the hippocampus is not simply a conduit for connecting neocortex to hippocampus. Thus, both the $\mathrm{H}^{++}$lesion and the PRPH lesion produced more severe memory impairment than the $\mathrm{H}^{+}$lesion. Accordingly, the cortex that was damaged in the $\mathrm{H}^{++}$ and PRPH lesions, but undamaged in the $\mathrm{H}^{+}$lesion, must also be important for memory function. The implication is that information from neocortex need not reach the hippocampus itself in order for some memory storage to occur. These considerations explain why memory impairment is increased by damage to cortical structures in addition to the hippocampus.

Another important conclusion is that the amygdaloid complex is not a component of the medial temporal lobe memory system and does not contribute to the kind of (declarative) memory that depends on this system (39). Experiments with both rats and monkeys suggest that the amygdala is important for other functions, including conditioned fear and the attachment of affect to neutral stimuli (40). The amygdala may also have a broader role in establishing links between stimuli, as in making associations among $\infty$ sensory modalities (41).

Additional evidence also supports the distinction between the functions of the hippocampal formation and the amygdala. For six different groups of monkeys that were given memory tests, quantitative ratings of emotional behavior were obtained (42). Partial or complete damage to the amygdaloid complex caused marked alter- o ations in emotional behavior. Specifically, monkeys were less fearful than normal and were unusually willing to touch and otherwise interact with novel stimuli. However, unless there was also damage to the hippocampal formation or adjacent cortex, memory was intact. Conversely, all groups with damage to hippocampal formation or $\mathbb{\mathscr { D }}$ associated cortex had memory impairment. Yet, unless there was also $\frac{E}{d}$ damage to the amygdala, emotional behavior was normal (Fig. 5).

In summary, these findings emphasize the importance for memory $\frac{\overline{1}}{\mathrm{C}}$ of the hippocampal formation and the perirhinal and parahippo- $n$ campal cortex of the medial temporal lobe. Other findings in monkeys and humans are consistent with this proposal (43). Medial temporal lobe cortex presumably participates in memory functions by virtue of its extensive reciprocal connections with putative memory storage sites in neocortex. Thus, disconnection of inferotemporal cortex (area TE) from the limbic system severely impaired memory (44). In contrast, damage to the fornix, which is a major subcortical efferent projection of the hippocampal formation, and damage to a major diencephalic target of the fornix, the mammillary nuclei, had only mild effects on memory $(30,45,46)$.
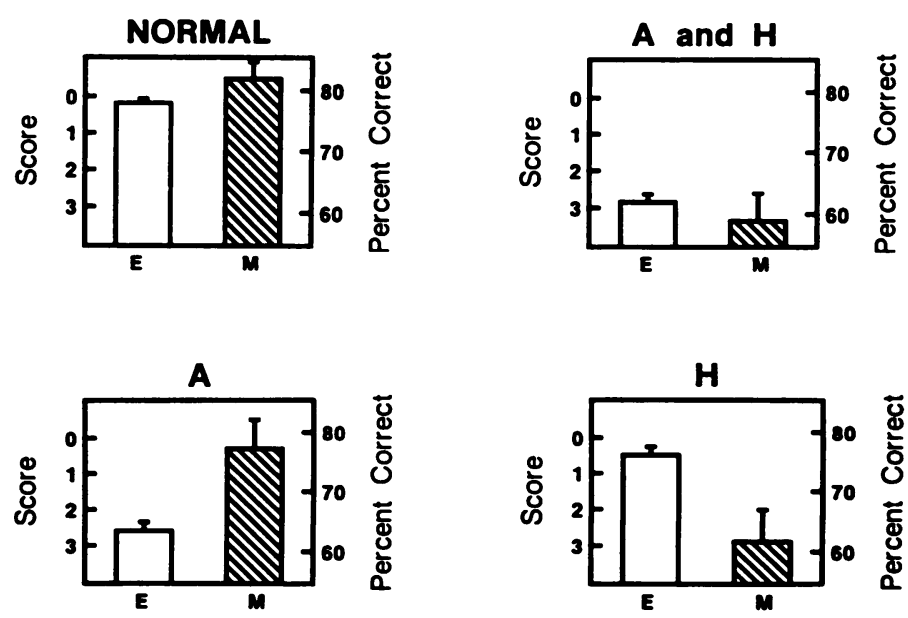

ARTICLES

1383 


\section{The Hippocampus}

Until recently, it has been difficult to determine in monkeys whether the hippocampus itself makes an essential contribution to memory function. A direct surgical approach to the hippocampus necessarily damages adjacent cortex (that is, entorhinal and parahippocampal cortex), and a stereotaxic approach based on a standard monkey brain atlas is problematic, because the size and shape of the hippocampus can vary considerably from monkey to monkey.

We have combined stereotaxic neurosurgery with MRI to improve the accuracy of surgical lesions within the hippocampus. Prior to surgery, $M R$ images were obtained from four monkeys with small radio-opaque landmarks anchored to the skull (47) (Fig. 2, C and D). The landmarks were then used to make bilateral hippocampal lesions (the $\mathrm{H}$ lesion). Monkeys sustained damage to the hippocampus, dentate gyrus, and subiculum, but the perirhinal, entorhinal, and parahippocampal cortices were almost entirely spared. At delays of $10 \mathrm{~min}$ in the nonmatching to sample task, monkeys with $\mathrm{H}$ lesions were as impaired as monkeys with $\mathrm{H}^{+}$lesions. On two other

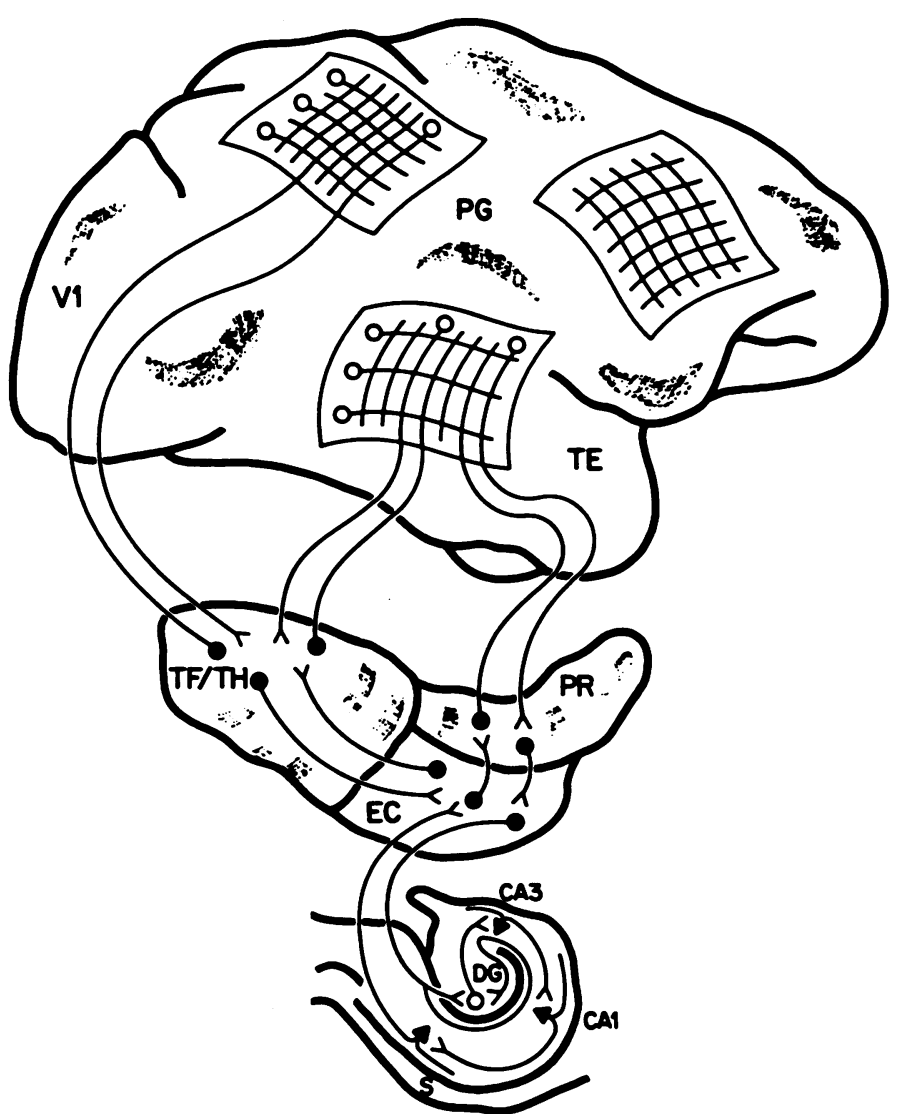

Fig. 6. Schematic drawing of primate neocortex plus the components of the medial temporal lobe memory system believed to be important in the transition from perception to memory. The networks in cortex show representations of visual object quality (in area TE) and object location (in area PG). If this distributed activity is to develop into a stable long-term memory, neural activity must occur at the time of learning along projections from these regions to the medial temporal lobe (first to the parahippocampal gyrus (TF/TH), perirhinal cortex (PR), and entorhinal cortex (EC), and then in the several stages of the hippocampus [the dentate gyrus (DG) and the $\mathrm{CA} 3$ and $\mathrm{CAl}$ regions]. The fully processed input eventually exits this circuit by way of the subiculum (S) and EC, where widespread efferent projections return to neocortex. The hippocampus and adjacent structures bind together or otherwise support the development of representations in neocortex, so that subsequently memory for a whole event (for example, represented in TE and PG) can be reactivated even from a partial cue. [Reprinted from (61) with permission, (C) F. K. Schattauer Verlagsgesellschaft mbH] tasks (retention of object discriminations and eight-pair concurrent discrimination learning), monkeys with $\mathrm{H}^{+}$lesions were significantly more impaired than $\mathrm{H}$ monkeys (47). These results provide direct support for the long-standing idea that the hippocampus itself is important for memory. They also emphasize the importance of the cortical regions adjacent to the hippocampus (specifically, the entorhinal and parahippocampal cortices that are damaged in the $\mathrm{H}^{+}$ lesion but not in the $\mathrm{H}$ lesion) (48).

We have also examined the effects of hippocampal damage by using a noninvasive procedure to produce global ischemia in the monkey (the ISC lesion). This method consistently produced significant bilateral cell loss in the $\mathrm{CAl}$ and $\mathrm{CA} 2$ fields of the hippocampus and the hilar region of the dentate gyrus (49). Cell loss was greater in the posterior portion of the hippocampus than in its anterior portion. On the delayed nonmatching to sample task, four monkeys with ISC lesions performed similarly to the three monkeys with $\mathrm{H}^{+}$lesions. Moreover, the impairment was long-lasting. On two other tasks, monkeys with ISC lesions performed better than monkeys with $\mathrm{H}^{+}$lesions $(P=0.06)$ and similar to monkeys with $\mathrm{H}$ lesions.

These findings from ISC monkeys suggest that even incomplete $\stackrel{\infty}{\circ}$ damage to the hippocampus is sufficient to impair memory in monkeys, $\mathrm{N}$ just as in humans (patient R.B.). It is possible that additional neural $\sigma^{\circ}$ damage occurred in the ISC monkeys and in R.B. and that such damage $\bar{\varnothing}$ was not detected in histological examination. Yet, the ISC monkeys obtained about the same memory scores as $\mathrm{H}$ monkeys and better memory scores than $\mathrm{H}^{+}$monkeys. Accordingly, it seems reasonable to suppose that the ISC animals (and by extension, patient R.B.) did not have substantial neuropathological change affecting memory that was not detected histologically. The damage produced by the ISC lesion to a critical component of hippocampal circuitry (that is, the CAl region) may be as disruptive to hippo-campal function as more extensive damage (the $\mathrm{H}$ lesion). Results from a rodent model of global ischemia are consistent with this view (50).

\section{Function of the Medial Temporal Lobe Memory System}

The medial temporal lobe memory system performs a critical function beginning at the time of learning, in order that representations can be established in long-term memory in an enduring and usable form. Coordinated and distributed activity in neocortex is thought to underlie perception and immediate (short-term) memory $(44,51)$. These capacities are unaffected by medial temporal lobe damage. However, if distributed cortical activity is to be transformed into stable long-term memory, then the hippocampus and related structures must be engaged at the time of learning (Fig. 6). The hippocampus and related structures may serve as a device for forming conjunctions between ordinarily unrelated events or stimulus features, which are processed and represented by distinct cortical sites (52). In this sense, the hippocampal system is a storage site for a simple memory, a summary sketch, or an index (53). As long as a percept is in view or in mind, its representation remains coherent in short-term memory by virtue of mechanisms intrinsic to neocortex. However, a problem potentially arises when attention shifts to a new percept or a new thought, and one then attempts to recover the original memory. We propose that the capacity for later retrieval is achieved because the hippocampal system has "bound together" the relevant cortical sites that together represent memory for a whole event.

The role of this system can be further described in two important ways. First, the hippocampal system is crucial for the rapid acquisition of new information about facts and events, which are then 
available as conscious recollections (19). Long-term potentiation (LTP) in the hippocampus (54) would be an appropriate mechanism for this specialized role of the hippocampus in rapidly forming conjunctions between unrelated events. In any case, many kinds of learning abilities (including skills, priming, habit learning, and simple forms of conditioning) (Fig. 3) lie outside the province of the medial temporal lobe memory system. Second, the role of this system is only temporary. In humans, very remote memory is unaffected by damage restricted to the medial temporal lobe (22). A prospective study of retrograde amnesia in the monkey showed that memories that depended initially on the integrity of the hippocampal formation gradually became reorganized (consolidated) so that during a period of several weeks they became independent of the hippocampal formation (55). Thus, as time passes after learning, more permanent memory develops, presumably as a result of slow synaptic change and in concert with normal forgetting. Remembering eventually becomes possible without the participation of the medial temporal lobe memory system.

\section{Conclusions}

Cumulative and systematic research with monkeys and related research with humans has identified the components of the medial temporal lobe memory system: the hippocampus, together with adjacent, anatomically related cortex (entorhinal, perirhinal, and parahippocampal cortex). This system is fast, has limited capacity, and performs a crucial function at the time of learning in establishing long-term declarative memory. Its role continues after learning during a lengthy period of reorganization and consolidation whereby memories stored in neocortex eventually become independent of the medial temporal lobe memory system. This process, by which the burden of long-term (permanent) memory storage is gradually assumed by neocortex, assures that the medial temporal lobe system is always available for the acquisition of new information. The anatomy and function of the system, and its relation to neocortex, is becoming well enough understood that computational modeling should provide a fruitful way to make these ideas more formal and quantitative.

\section{REFERENCES AND NOTES}

1. W. B. Scoville and B. Milner, J. Neurol. Neurosurg. Psychiatry 20, 11 (1957).

2. B. Milner, S. Corkin, H. L. Teuber, Neuropsychologia 6, 215 (1968); B. Milner, Clin. Neurosurg. 19, 421 (1972); S. Corkin, Semin. Neurol. 4, 249 (1984). H.M. developed amnesia at the age of 27 after bilateral medial temporal lobe resection a procedure carried out in an attempt to relieve severe epilepsy. He suffered profound memory impairment for day-to-day events, but retained normal intellectual ability (IQ), intact immediate memory, intact knowledge from early life, and a personality that according to the family was unchanged by the surgery.

3. F. C. Rose and C. P. Symonds, Brain 83, 195 (1960); A. R. Damasio et al., Arch. Neurol. 42, 252 (1985).

4. D. F. Benson, C. D. Marsden, J. L. Meadows, Acta Neurol. Scand. 50, 133 (1974).

5. B. T. Hyman, G. W. Van Hoesen, A. R. Damasio, C. L. Barnes, Science 225, 1168 (1984); G. W. Van Hoesen et al., Hippocampus 1, l (1991)

6. The hippocampal formation includes the dentate gyrus, the CA fields of the hippocampus proper, the subiculum, and entorhinal cortex. The term chippocampal region" was used originally (1) to denote the region occupied by the hippocampus and the cortex ventral to the hippocampus.

7. B. Milner, in The Neurosciences: Third Study Program, F. O. Schmitt and F. G. Worden, Eds. (MIT Press, Cambridge, MA, 1974), pp. 75-89.

8. E. Grunthal, Monatsschr. Psychiatr. Neurol. 113, I (1947); P. Glees and H. B. Griffith, Psychiatr. Neurol. Med. Psychol. 123, 193 (1952); M. Victor et al., Arch. Neurol. 5, 244 (1961); R. N. DeJong et al., Trans. Am. Neurol. Assoc. 93, 31 (1968); B. T. Woods et al., J. Neurol. Neurosurg. Psychiatry 45, 243 (1982); J. E. Cummings et al., Neurology 34, 679 (1984); C. C. Duychaerts et al., Ann. Neurol. 18, 314 (1985).

9. For reviews of studies with rats from this period, see [R. J. Douglas, Psychol. Bull. 67, 416 (1967); D. P. Kimble, ibid. 70, 285 (1968); R. L. Isaacson, The Limbic System (Plenum, New York, 1974)]. Investigations with monkeys began almost immediately after H.M.'s memory impairment was reported [J. Orbach, B. Milner, T. Rasmussen, Arch. Neurol. 3, 320 (1960)] and included studies by the surgeon who operated on H.M. [R. E. Correll and W. B. Scoville, J. Comp. Physiol. Psychol. 60, 175 (1965). For reviews from this period, see L. Weiskrantz, in Cognitive Processes of Nonhuman Primates, L. E. Jarrard, Ed. (Academic Press, New York, 1971), pp. 25-46; S. D. Iversen, Int. Rev. Neurobiol. 19, 1 (1976).

10. J. A. Horel, Brain 101, 403 (1978).

11. M. Mishkin, Nature 273, 297 (1978).

12. S. Zola-Morgan, L. R. Squire, D. G. Amaral, J. Neurosci. 6, 2950 (1986).

13. J. W. Olney, in Kainic Acid as a Tool in Neurobiology, E. G. McGeer, J. W. Olney, P. L. McGeer, Eds. (Raven, New York, 1978), pp. 95-121; B. K. Siesjo, J. Cereb. Blood Flow Metab. 1, 155 (1981); G. E. Fagg, Trends Neurosci. 8, 207 (1985); B. Meldrum, ibid., p. 47; D. W. Choi, ibid. 11, 465 (1988). Experimentally induced ischemia in rats damages the $\mathrm{CAl}$ region of hippocampus and produces enduring memory impairment [B. T. Volpe et al., Stroke 15, 558 (1984); H. P. Davis et al., Physiol. Behav. 37, 387 (1986); R. Auer et al., J. Neurosci. 9, 1641 (1989)].

14. M. Victor and D. Agamanolis, J. Cognit. Neurosci. 2, 246 (1990). This individua developed amnesia after a series of generalized seizures, and the lesion involved all the fields of the hippocampus and much of the dentate gyrus.

15. One index of the severity of memory impairment is the difference between the Wechsler Adult Intelligence Scale (WAIS IQ) and the Wechsler Memory Scale (WMS). Both tests yield a mean of 100 in the normal population with standard deviations of 15. The WAIS-WMS difference score for H.M. averaged for five different test administrations from 1955 to 1983 was 44 . The difference score for R.B. was 20.

16. G. A. Press, D. G. Amaral, L. R. Squire, Nature 341, 54 (1989).

17. L. R. Squire, D. G. Amaral, G. Press, J. Neurosci. 10, 3106 (1990).

18. M. Mishkin, J. Spiegler, R. C. Saunders, B. J. Malamut, in Toward a Treatment of Alzheimer's Disease, S. Corkin, K. L. Davis, J. H. Growdon, E. J. Usdin, R. J. Wurtman, Eds. (Raven, New York, 1982), Pp. 235-247; L. R. Squire and $S^{\infty}$ Zola-Morgan, in Physiological Basis of Memory, J. A. Deutsch, Ed. (Academic Presse New York, 1983), pp. 199-268; H. Mahut and M. Moss, in Neuropsychology of Memory, L. R. Squire and N. Butters, Eds. (Guilford Press, New York, 1984), ppo' 297-315.

19. L. R. Squire, Annu. Rev. Neurosci. 5, 241 (1982); M. Moscovitch, in Human⿳亠 Memory and Amnesia, L. Cermak, Ed. (Erlbaum, Hillsdale, NJ, 1982), ppE 337-370; N. Cohen, in Neuropsychology of Memory, L. R. Squire and N. Butters, Eds. (Guilford Press, New York, 1984), pp. 83-103; E. Tulving, Am. Psychol. 40, 385 (1985); L. Weiskrantz, Hum. Neurobiol. 6, 93 (1987); D. L. Schacter, J. Exp Psychol. Leam. Mem. Cognit. 13, 501 (1987); D. Hintzman, Annu. Rev. Psychol. $\frac{\mathrm{C}}{\mathrm{O}}$
41, 109 (1990).

20. R. Hirsch, Behav. Biol. 12, 421 (1974); D. Gaffan, J. Comp. Physiol. Psychol. 86, 근 1100 (1974); J. O'Keefe and L. Nadel, The Hippocampus as a Cognitive MapO (Oxford Univ. Press, London, U.K., 1978); D. S. Olton, J. T. Becker, G. E.ర் Handelmann, Behav. Brain Sci. 2, 313 (1979); M. Mishkin and H. L. Petri, in Neuropsychology of Memory, L. R. Squire and N. Butters, Eds. (Guilford, New York, 1984), pp. 287-296; R. W. Sutherland and J. W. Rudy, Psychobiology 17, 129 (1989); R. C. Saunders and L. Weiskrantz, Behav. Brain Res. 35, 85 (1989): H. Eichenbaum, P. Mathews, N. J. Cohen, Behav. Neurosci. 103, 1207 (1989). 21. S. Zola-Morgan and L. R. Squire, J. Neurosci. 4, 1072 (1984).

22. L. R. Squire, Psychol. Rev., in press.

23. S. Zola-Morgan, L. R. Squire, M. Mishkin, Science 218, 1337 (1982).

24. H. Mahut, M. Moss, S. Zola-Morgan, Neuropsychologia 19, 201 (1981)

25. S. Zola-Morgan and L. R. Squire, Behav. Neurosci. 99, 22 (1985).

26. L. R. Squire and S. Zola-Morgan, Trends Neurosci. 11, 170 (1988)

27. S. Zola-Morgan and L. R. Squire, in The Development and Neural Bases of Higher= Cognitive Functions, A. Diamond, Ed. (New York Academy of Sciences, New York? 1991), pp. 434-456.

28. In a subsequent study, anterior lesions of temporal stem white matter producedo memory impairment on a delayed matching to sample task [R. A. Cirillo, J. A을 Horel, P. J. George, Behav. Brain Res. 34, 55 (1989)]. Impaired performance wass observed at all delays including a no-delay (0-s) condition. However, monkeys witho $\mathrm{H}^{+} \mathrm{A}^{+}$removals perform normally when delay intervals are very short [0 to $5 \mathrm{Q}$ (59)]. Thus, it is not clear that the deficit after anterior temporal stem damage was the same as the memory deficit in monkeys with large medial temporal removals. Indeed, because the temporal stem carries a variety of fiber systems that interconnect widespread neocortical and subcortical areas, it is unlikely that an impairment observed after temporal stem damage would be limited to memory functions.

29. S. Zola-Morgan and L. R. Squire, Behav. Neurosci. 100, 165 (1986).

30. , D. G. Amaral, J. Neurosci. 9, 898 (1989).

31. H. Mahut, S. Zola-Morgan, M. Moss, ibid. 2, 1214 (1982).

32. E. A. Murray and M. Mishkin, ibid. 4, 2565 (1984)

33. According to signal detection analysis [J. L. Ringo, Behav. Neurosci. 102, 173 (1988)], monkeys with $\mathrm{H}^{+}$lesions are actually impaired equivalently whether or not training is given before the lesion is made. Prior training benefits normal and lesioned monkeys similarly and brings group scores closer together as performance approaches the maximum value ( $100 \%$ correct).

34. S. Zola-Morgan et al., J. Neurosci. 9, 1922 (1989). Performance was also normal on delayed response (at up to 30 -s delays), retention of object discriminations, and the eight-pair concurrent discrimination learning task.

35. J. T. Becker, J. A. Walker, D. S. Olton, Brain Res. 200, 307 (1980); H. Eichenbaum, A. Fagan, N. J. Cohen, J. Neurosci. 6, 1876 (1986); D. S. Olton, W. H. Meck, R. Church, Brain Res. 404, 180 (1987); R. J. Sutherland, R. J. McDonald, C. R. Hill, J. W. Rudy, Behav. Neural Biol. 52, 331 (1989); R. J. Sutherland and R. J. McDonald, Behav. Brain Res. 37, 57 (1990).

36. R. Insausti, D. G. Amaral, W. M. Cowan, J. Comp. Neurol. 264, 356 (1987).

37. R. P. Clower, S. Zola-Morgan, L. R. Squire, Soc. Neurosci. Abstr. 16, 616 (1990). In Fig. $4 \mathrm{~A}$, one of the three animals in the $\mathrm{H}^{++}$group required a remedial procedure in which the sample object was always presented twice instead of once. 
Accordingly, the performance curve for the $\mathrm{H}^{++}$group in Fig. 4A may underestimate the deficit. The $\mathrm{H}^{++}$monkeys were as impaired as $\mathrm{H}^{+} \mathrm{A}^{+}$monkeys on a second task, retention of object discriminations $(68.4 \%$ versus $69.5 \%$ correct, respectively, averaged across four discriminations, each tested on three different days).

38. S. Zola-Morgan et al., J. Neurosci. 9, 4355 (1989).

39. We propose that effects on memory reported in previous studies with $\mathrm{A}^{+}$lesions are due to damage to perininal cortex that necessarily occurs during the surgical approach to the amygdala [R. C. Saunders, E. A. Murray, M. Mishkin, Neuropsychologia 22, 785 (1984); E. Murray and M. Mishkin, J. Neurosci. 6, 1991 (1986); or the amygdalofugal pathway [J. Bachevalier, J. K. Parkinson, M. Mishkin, Exp. Brain Res. 57, 554 (1985)]. See also (11). For a similar interpretation of the earlier work, see [E. Murray, in The Amygdala, J. Aggleton, Ed. (Wiley, New York, in press)].

40. M. Davis, Behav. Neurosci. 100, 814 (1986); D. Gaffan and S. Harrison, J. Neurosci. 7 , 2285 (1987); J. E. LeDoux, in Handbook of Physiology: The Nenvous System V. Higher Functions of the Nerwous System, J. M. Brookhart and V. B. Mountcastle, Eds. (American Physiological Society, Bethesda, MD, 1987), vol. 5, pp. 419-460; M. Gallagher et al., J. Neurosci. 10, 1906 (1990); R. P. Kesner, in The Amygdala, J. Aggleton, Ed. (Wiley, New York, in press).

41. E. A. Murray and M. Mishkin, Science 228, 604 (1985).

42. S. Zola-Morgan et al., Hippocampus 1, 207 (1991).

43. These include pioneering studies of cooling the temporal cortex in monkeys [J. A. Horel and D. E. Pytko, J. Neurophysiol. 47, 11 (1982); J. A. Horel and D. E. Pytko-Joiner, M. Voytko, K. Salsbury, Behav. Brain Res. 23, 29 (1987)], studies of local cerebral glucose utilization in monkeys during the performance of memory tasks [H. R. Friedman and P. S. Goldman-Rakic, J. Neurosci. 8, 4693 (1988)], studies of normal human memory with positron emission tomography [L. R. Squire et al., Soc. Neurosci. $A b s t r .$, in press], and neuropsychological studies of cognitive impairment [H. Damasio and A. R. Damasio, Lesion Analysis in Neuropsychology (Oxford Univ. Press, New York, 1989)].

44. M. Mishkin, Philos. Trans. R. Soc. London B 298, 85 (1982)

45. J. P. Aggleton and M. Mishkin, Exp. Brain Res. 58, 190 (1985); J. Bachevalier, R. Saunders, M. Mishkin, ibid. 57, 547 (1985).

46. Medial thalamic lesions in monkeys and humans can produce severe memory impairment [M. Victor, R. D. Adams, G. H. Collins, The Wemicke-Korsakoff Symdrome (Davis, Philadelphia, ed. 2, 1989); J. P. Aggleton and M. Mishkin, Neuropsychologia 21, 189 (1983); D. Y. von Cramon, N. Hebel, U. Schuri, Brain 108, 993 (1985); N. R. Graff-Radford, D. Tranel, G. W. Van Hoesen, J. Brandt, ibid. 113, 1 (1990)], perhaps by virtue of the projections to the medial thalamus that originate in the hippocampus as well as in entorhinal cortex and perirhinal cortex [D. G. Amaral, in Handbook of Physiology: The Nervous System: Higher Functions of the Nerwous System, J. M. Brookhart and V. B. Mountcaste, Eds. (American Physiological Society, Bethesda, MD, 1987), vol. 5, pp. 211-294]. Enduring memory impairment can also occur after damage to the cholinergic basal forebrain [A. R. Damasio, N. R. Graff-Radford, P. J. Eslinger, H. Damasio, N. Kassell, Arch. Neurol. 42, 263 (1985)], which has strong anatomical connections to medial temporal lobe structures [M.-M. Mesulam, E. J. Mufson, A. I. Levy, B. H. Wainer, J. Comp. Neurol. 214, 170 (1983)]
47. P. Alvarez-Royo, R. Clower, S. Zola-Morgan, L. R. Squire, J. Neurosci. Methods, in press; R. Clower, P. Alvarez-Royo, S. Zola-Morgan, L. R. Squire, Soc. Neurosci. Abstr., in press.

48. Results from rodents are similar to the findings from $\mathrm{H}$ and $\mathrm{H}^{+}$monkeys in that damage involving the hippocampus proper plus the subiculum produced more memory impairment than damage limited to the hippocampus [L. E. Jarrard, in The Hippocampus, R. L. Isaacson and K. H. Pribram, Eds. (Plenum, New York, 1986), vol. 4, pp. 93-126; R. G. M. Morris, F. Schenk, F. Tweedie, L. E. Jarrard, Eur. J. Neurosci. 2, 1016 (1990)]

49. S. Zola-Morgan et al., Soc. Neurosci. Abstr. 15, 341 (1989); S. Zola-Morgan and L. R. Squire, in The Biology of Memory, L. R. Squire and E. Lindenlaub, Eds. (Schattauer Verlag, Stuttgart, 1990), pp. 509-521; N. Rempel, R. Clower, D. G. Amaral, S Zola-Morgan, L. R. Squire, Soc. Neurosci. Abstr., in press. Global ischemia was produced by $15 \mathrm{~min}$ of bilateral carotid occlusion together with pharmacologically induced hypotension.

50. H. P. Davis and B. Volpe, in The Biology of Memory, L. R. Squire and E Lindenlaub, Eds. (Schattauer Verlag, Stuttgart, 1990), pp. 477-504.

51. L. R. Squire, Memory and Brain (Oxford Univ. Press, New York, 1987); A. R. Damasio, Cognition 33, 25 (1989); W. Singer, Concepts Neurosci. 1, 1 (1990).

52. L. R. Squire, A. P. Shimamura, D. G. Amaral, in Neural Models of Plasticity, J. Byrne and W. Berry, Eds. (Academic Press, New York, 1989), pp. 208-239.

53. D. Marr, Philos. Trans. R. Soc. London B 176, 23 (1971); B. McNaughton and L. Nadel, in Neuroscience and Connectionist Theory, $N$... Gluck and D. Rumelhart, Eds. (Erlbaum, Hillsdale, NJ, 1990), pp. 1-63.

54. T. V. P. Bliss and T. Lomo, J. Physiol. (London) 232, 331 (1973).

55. S. Zola-Morgan and L. R. Squire, Science 250, 288 (1990).

56. L. R. Squire et al., Behav. Neurosci. 102, 210 (1988); J. P. Aggleton et al. Neuropsychologia 26, 265 (1988).

57. D. P. Salmon, S. Zola-Morgan, L. R. Squire, Psychobiology 15, 37 (1987).

58. B. L. Malamut, R. C. Saunders, M. Mishkin, Behav. Neurosci. 98,759 (1984).

59. W. H. Overman, G. Ormsby, M. Mishkin, Exp. Brain Res. 79, 18 (1990).

60. Skills and habits may depend on the neostriatum [M. Packard, R. Hirsch, N. White, $J$ Neurosci. 9, 1465 (1989; J. Wang, T. Aigner, M. Mishkin, Soc. Neurosci. Abstr. 16, 617 \) (1990); J. Saint-Cyr, A. Taylor, A. Lang, Brain 111, 941 (1988); W. Heindel, D. है Salmon, C. Shults, P. Walicke, N. Butters, J. Neurosci. 9, 582 (1989)]. For information \) about the neural substrates of other kinds of nonderlarative memory, see (40). Also see E. Tulving and D. Schacter, Science 247, 385 (1990); L. R. Squire et al., Soc. Neurosci. Abstr., in press; R. F. Thompson, Science 233, 941 (1986); M. Davis, T. Parsi, D. Gendelman, M. Tischler, J. Kehne, ibid. 218, 688 (1982); R. Leaton and W. Supple, Jr., O ibid. 232, 513 (1986)

61. L. R. Squire, in The Biology of Memory, L. R. Squire and E. Lindenlaub, Eds. (Schattauer Verlag, Stuggart, 1990), pp. 643-664.

62. We thank D. Amaral P. Alverez-Royo, R Clower, N. Remple, and W. Suzuki for their contributions to the work summarized here. Supported by the Medical Research Service of the Department of Veterans Affairs, the Office of Naval Research, NIH grant NS19063, NIMH grant MH24600, and the McKnight Foundation.

\title{
Reexamination of the Folding of BPTI: Predominance of Native Intermediates
}

\author{
Jonathan S. Weissman and Peter S. Kim
}

Bovine pancreatic trypsin inhibitor (BPTI) continues to be the only protein for which a detailed pathway of folding has been described. Previous studies led to the conclusion that nonnative states are well populated in the oxidative folding of BPTI. This conclusion has broadly influenced efforts to understand protein folding. The population of intermedi-

$\mathrm{E}$ FFORTS TO UNDERSTAND PROTEIN FOLDING ARE HAMpered by the transient nature of kinetic folding intermediates. In a series of pioneering studies $(1,2)$ begun in the mid-

The authors are in the Howard Hughes Medical Institute, Whitehead Institute for Biomedical Research, 9 Cambridge Center, Cambridge, MA 02142. In addition, J. S. Weissman is in the Department of Physics and P. S. Kim is in the Department of Biology, Massachusetts Institute of Technology, Cambridge, MA ates present during the folding of BPTI has been reexamined by modern separation techniques. It was found that all well-populated folding intermediates contain only native disulfide bonds. These data emphasize the importance of native protein structure for understanding protein folding.

1970s, this difficulty was circumvented by trapping disulfide-bonded folding intermediates, and the folding pathway of bovine pancreatic trypsin inhibitor (BPTI) was described in terms of the intermediates that accumulate substantially during folding. Native BPTI (N) contains three disulfide bonds (Fig. 1), indicated by the cysteines involved $(3)$ as $[30-51 ; 5-55 ; 14-38]$. The protein unfolds on reduction of these disulfide bonds, even in the absence of denaturants. Although there are $\mathbf{7 5}$ possible species of BPTI con- 